\title{
Micropolíticas de exclusão: as dificuldades no acesso e permanência das pessoas trans na educação
}

André Lucas Guerreiro Oliveira ${ }^{1}$

\section{RESUMO}

Pretende-se discutir neste artigo as dificuldades que as pessoas trans apresentam para o acesso e a permanência nos ambientes educacionais. É de amplo conhecimento que a transfobia - violência, preconceito e discriminação que as pessoas trans sofrem - é causadora de grandes dificuldades e desafios na vida destas pessoas, em todos os espaços de convivência, e não seria diferente nas instituições de ensino. Infelizmente, na escola também se aprende e ensina como reproduzir preconceitos e desrespeito às diferenças. $\mathrm{O}$ ambiente escolar e o universitário muitas vezes chegam a ser tão hostis às pessoas trans que é frequente a desistência precoce dos estudos. Ainda hoje (mesmo que haja avanços) é incomum a cena de uma pessoa trans que concluiu o ensino superior; ao ponto de que a notícia de uma mulher ou um homem trans finalizando uma pósgraduação, ganha enorme repercussão e notoriedade principalmente nos meios de divulgação nas mídias digitais, como as redes sociais. Neste sentido, o trabalho almeja problematizar estas dificuldades denominandoas como micropolíticas de exclusão, a partir de um referencial foucaultiano. Tais micropolíticas são produzidas nos espaços educacionais e geram desconforto e adversidades para as pessoas trans, obrigando-as muitas vezes a abandonarem os estudos. Salienta-se que se existem poucas políticas de acesso, as políticas para a permanência ainda são incipientes e precárias.

Palavras-Chave: Pessoas trans. Educação. Acesso e permanência.

Doutorando em Educação pelo PPGE da UFPR, professor de Sociologia da rede pública do estado do PR e do curso pré-vestibular gratuito Em Ação, bolsista CAPES, andre.guerreiro13@outlook.com 
Este artigo propõe discutir alguns obstáculos no acesso e na permanência nas instituições de ensino da população de pessoas trans do país. Antes de prosseguir, faz-se necessário uma pequena digressão a respeito das denominações a serem utilizadas. Compreende-se como pessoas trans toda a gama de pessoas que apresentam alguma não conformidade entre o gênero que lhes foi atribuído em seu nascimento ${ }^{2}$ e o gênero que vivenciam, a saber: transexuais, travestis e transgêneros ${ }^{3}$. Não me limitarei a apenas uma destas subdivisões, uma vez que no interior do movimento social ainda há uma disputa pelos melhores termos que trazem maior representação as/aos participantes da comunidade. Não sendo intuito deste trabalho resolver esta circunstância, bem como não há interesse de refletir somente sobre as dificuldades no acesso e permanência nas instituições de ensino de algum tipo de identidade trans.

Com vistas a dar maior entendimento acerca das terminologias será utilizada a nomenclatura mais empregada nas discussões contemporâneas no campo das Ciências Sociais e Humanas, em detrimento à terminologia convencional das ciências médicas. Portanto, ao se fazer referência aos homens trans estarei discorrendo sobre pessoas que foram designadas como mulheres no momento de seu nascimento; por possuírem a genitália marcada como feminina (vagina) e que por qualquer motivo, em algum momento de suas vidas, passaram a se reconhecer como pertencentes ao

\footnotetext{
2 Vale salientar que neste momento estou me referindo à construção generificada típica das sociedades capitalistas ocidentais. Como gênero não é uma categoria biológica, as possibilidades de atuá-lo varia de sociedade em sociedade, assim como também em períodos históricos diferentes.

3 Embora este termo não seja amplamente usado no contexto brasileiro, inclusive provocando algumas divergências no movimento social de pessoas trans opto por elencá-lo na tentativa de abarcar todo o espectro desta população. Também, como ainda não iniciei as entrevistas para o trabalho de campo, é preciso garantir que os/as entrevistados sejam referenciados como se denominam.
} 
gênero masculino, logo homens. Para além de concordar com as Ciências Sociais; prefiro utilizar esta denominação por refutar a classificação médica (e patologizante) que elenca tais pessoas como "transexuais femininas". A forma médica de rotular as pessoas trans mantém o indivíduo no gênero ao qual não se identifica, ainda que a pessoa já tenha concluído todas as exigências de transformação corporal para não ser mais caracterizada como "feminina". Partindo da mesma linha de raciocínio, ao citar mulheres trans me reportarei a pessoas que ao nascerem foram identificadas como homens por possuírem pênis e que por qualquer motivo em algum momento de suas vidas decidem vivenciar o gênero feminino.

Muito recentemente tem crescido o interesse da população trans pelo espaço da Educação, seja pela entrada ou retomada dos estudos na escola/ e ou universidade, seja pelas discussões que amparam as temáticas de gênero e diversidade na educação. Este interesse pode ser averiguado tanto pela inserção do movimento social institucionalizado nos espaços de controle social que disputam as questões educacionais; quanto pela atuação mesma da comunidade de pessoas trans que em atos de persistência e resistência passam a elencar o espaço escolar/universitário como um espaço a ser frequentado, dado que se trata de locais de relações de poder.

É de amplo conhecimento que a transfobia - preconceito e discriminação que as pessoas trans sofrem - é causadora de grandes dificuldades e desafios na vida destas pessoas. Em todos os espaços de convivência, e não seria diferente nas instituições de ensino. Infelizmente, na escola também se aprende e ensina como reproduzir preconceitos e desrespeito às diferenças. $\mathrm{O}$ ambiente escolar muitas vezes chega a ser tão hostil às pessoas trans que é frequente a desistência precoce dos estudos. Ainda hoje é tão incomum a cena de uma pessoa trans que concluiu o ensino superior; que quando há a notícia de uma mulher ou um homem trans que finaliza uma pós- 
graduação, ganha enorme repercussão e notoriedade ${ }^{4}$, principalmente nos meios de divulgação nas mídias digitais, como as redes sociais. Porém, não apenas nos veículos de comunicação mais informais como a internet estas notícias circulam. Atualmente a frequência dos debates sobre o uso do nome social e de banheiros por pessoas trans na escola vem ganhando espaço cada vez maior em meios de comunicação de massa mais tradicionais, como diversos programas televisivos.

Se até pouco tempo a escola/universidade não estava no foco das pretensões da população trans isso não pode mais ser aceito como verdade.

No contexto atual da cena política brasileira debates vêm sendo pleiteados acerca do que as correntes mais conservadoras optam por denominar por “ideologia de gênero". Tal denominação evidencia o intuito de desmerecer toda uma produção teórica em gênero e sexualidade já estabelecida. Este movimento político conservador - militante contra a "ideologia de gênero" (que na maioria das vezes se reconhece como apolítico) produziu vasta literatura encadeada à educação para a manutenção e reprodução de um pensamento biologizante e religioso quanto às questões e relações de gênero e sexualidade humana.

Neste sentido, é possível afirmar o caráter político deste artigo. Tenho plena consciência e responsabilidade de que a discussão proposta está inserida num campo de disputa de ideias, em que compreensões sobre o que é gênero, o que é homem e mulher, o que é transexualidade, travestilidade e transgeneridade, quais corpos e vidas são viáveis e têm garantido o direito de estar no escola/universidade estão sendo problematizados. Com isso

4 A título de exemplo cito a grande repercussão que a defesa do doutoramento de Megg Rayara Gomes de Oliveira trouxe, tanto nas redes sociais, como em outros meios de comunicação de massa. Megg é a primeira travesti negra a se tornar doutora no país. Sua tese foi aprovada pelo departamento de Educação da UFPR em 30 de março de 2017. Para maiores informações consulte: http://www.ufpr.br/portalufpr/blog/noticias/pelaprimeira-vez-travesti-negra-defende-tese-de-doutorado-na-ufpr/ 
também se pontua que o trabalho buscou sempre que possível uma maior articulação com os saberes produzidos pela população em questão, ainda que saberes muitas vezes mais informais, tidos como subalternos ou subalternizados.

Vale salientar que a escolha desta temática começou por revelar-se durante a realização da pesquisa de mestrado na área de Sociologia. Muitos dos interlocutores trouxeram a temática da escola (e/ou universidade) em suas narrativas, muito embora esse não fosse o foco daquele trabalho. Como a pesquisa versava sobre homens trans, a inquietação com as questões das instituições escolares e a população trans já se fazia presente. Com o desenrolar da análise tornou-se evidente que o tema merecia uma averiguação teórica e empírica maior.

Quando afirmo que esta pesquisa se insere num campo político, numa discussão com vistas à proposição de uma argumentação política, é possível mobilizar Maria Célia Marcondes de Moraes (2009), dado que a autora defende o papel político da teoria, buscando denunciar a banalização do esforço teórico. Embora seja uma autora crítica das teorizações pósmodernas e as culpabilize por tal banalização, penso que a leitura de seu texto auxilia minha postura de teorizar politicamente. Para a autora

\footnotetext{
é a capacidade de pôr uma finalidade, de projetar o resultado de uma determinada prática e de rastrear seus resultados que distingue o agir humano do comportamento meramente biológico, fundamentalmente instintivo. A transformação de um resultado ideal (uma mesa previamente pensada, uma aula previamente preparada) num resultado efetivo (uma mesa real ou uma aula, exatamente como planejadas) é a objetivação de um produto ideal, anteriormente pensado. (MORAES, 2009, p. 598).
}

No texto de Joan Scott (1995) podem-se encontrar correlações com o texto de Moraes - mesmo que seja preciso uma boa dose de esforço interpretativo 
- uma vez que para Scott também importa as consequências do uso da categoria analítica de gênero.

Nesta perspectiva a autora elabora uma refinada definição de gênero, denotando seu aspecto relacional, como uma construção histórica e cultural, o que traz para os contemporâneos estudos de gênero um olhar bastante complexificador destas relações.

Para Scott "o gênero é um elemento constitutivo de relações sociais baseado nas diferenças percebidas entre os sexos, e o gênero é uma forma primeira de significar as relações de poder." (SCOTT, 1995, p. 86).

É pertinente também informar de que quando meus interlocutores da pesquisa do mestrado eram informados de que sou professor de Sociologia do Ensino Médio, os mesmos buscavam aproximação, e não raro pediam que de alguma forma eu intercedesse por suas situações. E quando divulgavam minha pesquisa entre seus amigos, estes também entravam em contato. Sempre me solicitavam toda sorte de conselhos, buscando auxílio para estratégias para diminuir suas dificuldades no espaço escolar, contavam em pormenores suas lutas para permanecer na escola, pediam dicas de como enfrentar os vestibulares e sobreviver no ambiente acadêmico. Umas poucas vezes solicitaram que eu contribuísse com algum tipo de intervenção.

De alguma forma, embora o tema da minha dissertação não fosse a Educação, quando este era o tema, eu precisava estar disposto a trocar. Surge daí minha indagação quanto este paradoxo: por que mesmo apresentando tantas dificuldades em existir nas instituições de ensino, eles desejavam tanto, se empenhavam tanto em lá permanecer? Por que um local que não acolhe pessoas trans vinha se tornando tão importante para essas existências? Logo, na pesquisa do doutorado venho investigando as dificuldades no acesso e na permanência das pessoas trans nas instituições 
de ensino. Embora ainda não tenha realizado as entrevistas, os primeiros contatos tem sido reveladores e sempre que comento o tema Educação, as pessoas trans em conversas informais (pessoalmente ou nas redes sociais) abordam situações que enfrentaram e/ou ainda enfrentam nos ambientes educacionais.

Obviamente existem pessoas trans que já estão inseridas nos vários níveis de ensino, ainda assim trata-se de uma minoria, embora esse contexto venha se alterando em decorrência das lutas e avanços do movimento social. Contudo, se ainda apenas uma minoria no interior de outra minoria acessa integralmente a educação, a regra transforma-se em exceção, e um direito de todos e todas é limitado a alguns e algumas. Certamente, as intersecções entre gênero raça e classe se sobrepõem e implicam em efeitos diferenciados para as pessoas que escapam dos outros marcadores de "normalidade".

Nesta perspectiva, penso ser possível inferir que as dificuldades das pessoas trans para permanecer nos espaços educacionais tem a ver com o modo como a sociedade hierarquiza e define quem pode ter seus direitos plenamente garantidos e quem pode tê-los violados. Além da concepção do direito à Educação como universal, está em jogo quem é considerado cidadão/ã para ter acesso aos benefícios da lei. Em alguns momentos, as formas de exclusão são tão efetivas, que evidencia toda uma lógica em desconsiderar a própria humanidade da população trans.

Há recentes debates que trazem uma noção de grande importância para a compreensão dos fenômenos que hierarquizam as pessoas trans como menos humanas. Não apenas a normatividade heterossexual ${ }^{5}$ é responsável

5 Judith Butler (2015), filósofa estadunidense e influente estudiosa da teoria queer, compreende a heteronormatividade como a habilidade que torna capaz a heterossexualidade tornar-se a norma social que regula e determina a possibilidade de vidas, as quais estejam rigorosamente circunscritas em seus limites. Como também a 
por tal construção assimétrica de poder. Há também a normatividade cis. "Cis" é a abreviação do termo cisgênero. Pessoa cisgênero é aquela que não tem discordância com o gênero atribuído no momento do nascimento. Esta discordância a que aludo é fruto das relações sociais de nossa sociedade atual que propõe e engessa as possibilidades de vivência de gênero, em apenas dois pólos, o masculino e o feminino. Atrelando e biologizando o gênero masculino aos corpos com pênis e o gênero feminino aos corpos com vagina, ou seja, binarizando o gênero a partir da anatomia/fisiologia. Tal normatização do gênero avança também no desejo sexual dos sujeitos, propondo uma correspondência a ser seguida entre sexo, gênero e desejo, em que a heterossexualidade é expressão esperada da sexualidade. A binariedade compulsória do gênero é algo produzido então em nossa sociedade, portanto fruto das relações sociais. Sendo assim pode ser questionado e performatizado de diferentes modos, uma vez que:

[...] não há razão para supor que os gêneros também devam permanecer em número de dois. A hipótese de um sistema binário dos gêneros encerra implicitamente a crença numa relação mimética entre gênero e sexo, na qual o gênero reflete o sexo ou é por ele restrito. Quando o status construído do gênero é teorizado como radicalmente independente do sexo, o próprio gênero se torna um artifício flutuante, com a consequência de que homem e masculino podem, com igual facilidade, significar tanto um corpo feminino como um corpo masculino, e mulher e feminino, tanto um corpo masculino quanto feminino. (BUTLER, 2015, p. 26) [grifos no original].

O vocábulo "cis" é bastante proposto, discutido e difundido pela própria população de pessoas trans; as quais forjaram um termo para dar conta de explicitar os privilégios e as relações desiguais de poder entre as pessoas que não vivenciam a experiência de contrariar as normas de gênero - os/as

impossibilidade de vidas que estejam delimitadas para fora do que baliza, ou seja, é a norma que (re) produz corpos, gêneros e sexualidades; ou tidos como normais e humanos indivíduos sem nenhuma discordância entre a sua genitália e seu gênero, sem a necessidade de reforçar a obrigação com a heterossexualidade - e os outros corpos, lançados à margem da norma, os corpos abjetos. 
cisgêneros - e as pessoas trans, cujas vidas são marcadas pelo constante desafio de existir fora dos padrões impostos pela sociedade generificada.

Segundo Letícia Lanz (2014) acerca da noção cis:

\begin{abstract}
O termo cisgênero tem circulado na Internet pelo menos desde 1994, quando apareceu no alt.transgendered.usenet em um correio enviado por Dana Leland Defosse. Nele, Defosse não define o termo e parece assumir que os leitores já estão familiarizados com ele. A cunhagem do termo, segundo ela, deve ser atribuída a Carl Buijs, um homem transexual da Holanda, que usou o termo em diversas publicações suas na Internet. Buijs afirmou mais tarde, em outro correio, que - "quanto à origem do termo, eu apenas o compus e coloquei em uso". (LANZ, 2014, p. 17).
\end{abstract}

Atualmente há um debate entre alguns acadêmicos/as brasileiros/as e pessoas trans, algumas delas também inseridas na academia e altamente intelectualizadas, pela necessidade do termo. Ressalta-se que o termo vem ganhando grande difusão no contexto brasileiro (com a utilização até mesmo em meios de comunicação de massa), sendo impossível na atualidade desconsiderar esta conceituação, bem como sua potência em denunciar um sistema que hierarquiza, desqualifica, estigmatiza e violenta pessoas trans, a saber: o sistema cissexista e cisnormativo. Algumas pessoas trans, numa atitude de enfrentamento, ironicamente referem-se ao “cistema”.

Adentrando na temática das instituições de ensino e os efeitos de suas relações de poder na vida dos indivíduos e das populações é necessário voltar o olhar para as teorizações de Michel Foucault.

Foucault (1988 e 1999) descreve o aparecimento de uma nova abordagem do poder, a partir do século XVIII, denominando de biopoder. Tal poder tem como rota não mais o corpo enquanto indivíduo, porém o corpo-espécie, o corpo populacional. $\mathrm{O}$ autor não postula que o que descreve anteriormente 
como poder disciplinar teria sido suplantado, ao invés, aponta para uma combinação destas duas faces do poder, em que:

\begin{abstract}
a disciplina tenta reger a multiplicidade dos homens na medida em que essa multiplicidade pode e deve redundar em corpos individuais que devem ser vigiados, treinados, utilizados, eventualmente punidos. E, depois, a nova tecnologia que se instala se dirige a multiplicidade dos homens, não na medida em que eles se resumem em corpos, mas na medida em que ela forma, ao contrário, urna massa global, afetada por processos de conjunto que são próprios da vida, que são processos como o nascimento, a morte, a produção, a doença, etc. Logo, depois de urna primeira tomada de poder sobre o corpo que se fez consoante o modo da individualização, temos uma segunda tomada de poder que, por sua vez, não é individualizante mas que e massificante, se vocês quiserem, que se faz em direção não do homem-corpo, mas do homem-espécie. (FOUCAULT, 1988, p. 289).
\end{abstract}

Neste sentido, a vida humana passa a ser alvo do Estado. Se o poder soberano era exercido no direito de causar a morte ou de permitir a sobrevivência, há uma transformação nesta equação no aparecimento do biopoder, posto que a vida está no centro do poder. "O poder já não conhece a morte. No sentido estrito, o poder deixa a morte de lado" (FOUCAULT, 1988, p. 296), sendo então necessário "fazer viver e deixar morrer".

A estratégia do biopoder é a biopolítica, definição foucaultiana "para designar o que faz com que a vida e seus mecanismos entrem no domínio dos cálculos explícitos e faz do poder-saber um agente de transformação da vida humana." (FOUCAULT, 1999, p. 134). Este poder no qual a vida humana (enquanto espécie e não individual) necessita de mecanismos reguladores, atuando continuamente e corretivamente. Logo, opera por uma "atuação da norma.” (FOUCAULT, 1999, p.135), e a lei passa, cada vez mais a atuar como norma, constituindo uma sociedade de normalização, sendo esta "um efeito histórico de uma tecnologia de poder centrada na vida." (FOUCAULT, 1999, p.135). 
Foucault apresenta o dispositivo da sexualidade como um dos agenciamentos concretos que constituirão o biopoder. $\mathrm{O}$ autor diverge da ideia de que o século XVIII seria o início da época da repressão sexual, para ele, o que se dá é uma explosão discursiva do sexo, um refinamento do vocabulário autorizado em que surge a "polícia dos enunciados". Haveria uma multiplicação dos discursos sobre o sexo no próprio campo de exercício do poder. Não se trata de interdição ao sexo: "Censura sobre o sexo? Pelo contrário, constituiu-se uma aparelhagem para produzir discursos sobre o sexo, cada vez mais discursos, suscetíveis de funcionar e de serem efeito de sua própria economia." (FOUCAULT, 1999, p. 26). Esta tal aparelhagem ele denomina de dispositivo da sexualidade, ou seja, um dispositivo político o qual faz proliferar discursos sobre o sexo. Contudo, a análise da sexualidade como dispositivo político não suprime o corpo, o biológico.

As instituições de ensino também operam de maneira cisheteronormativa. Não à toa os relatos das pessoas trans em suas memórias dos tempos escolares muitas vezes são permeados por histórias de exclusão, de rechaço, de abandono e de negligência. É muito comum ouvir narrativas de pessoas trans que desistiram dos estudos muito precocemente por conta da não aceitação de sua identidade na escola. São várias as negativas que as pessoas trans recebem, e a imposição do modelo "normal" é sempre relatado.

Os ambientes de ensino, em quaisquer dos níveis são exemplos típicos de espaços onde episódios de exclusão são comuns à vida das pessoas trans, ou como disse Berenice Bento

\footnotetext{
$\mathrm{Na}$ verdade, há um desejo em eliminar e excluir aqueles que contaminam o espaço escolar. Há um processo de expulsão e não de evasão. É importante diferenciar "evasão" de "expulsão", pois, ao apontar com maior precisão as causas que levam crianças a não frequentarem o espaço escolar, teremos como enfrentar com eficácia os dilemas que constituem o cotidiano escolar, entre
} 
eles, a intolerância alimentada pela [trans] homofobia. (BENTO, 2008, 129).

Dayana Brunetto Carlin dos Santos (2010) ao refletir sobre a experiência da transexualidade na escola aponta para uma variedade de dados que podem influenciar nos processos de desistência dos estudos. Ainda que não considere a relação de transfobia sofrida com o afastamento da escola como causal argumenta que "importa considerar os diversos elementos que articulam esse afastamento da instituição." (SANTOS, 2010, p. 176). Para a pesquisadora, no caso das pessoas trans, o processo de abandono dos estudos não é unilateral, ou em suas palavras: "talvez seja produtivo pensar que não são transexuais e travestis que abandonam a escola, mas a escola é que as/os abandonam." (Ibid., p. 176).

Nome social é a denominação do que se convencionou no Brasil para descrever a utilização do nome que as pessoas trans escolhem de acordo com o gênero que vivem, com a intenção de evitar todos os constrangimentos do uso do nome civil quando ainda não retificado, como também é uma forma de "dar vida e materialidade" ao seu gênero vivido, posto que ter uma identidade masculina e ser referido por um nome feminino, ou vice e versa, é uma situação que tende a gerar desconforto e dificuldades. Em alguns casos, a utilização do nome social é permitido em estabelecimentos públicos, como universidades e órgãos públicos.

O uso do nome social nas instituições de ensino é um mecanismo acionado para a permanência e conclusão dos estudos. Em setembro de 2017 foi aprovado por unanimidade no Conselho Nacional de Educação o parecer que autoriza o uso de nome social nas escolas de educação básica. Com esta resolução, a utilização do nome social por pessoas trans passa a ser normatizada nas instituições de ensino. No entanto, não são raros os relatos de que nem sempre este direito é respeitado. 
De acordo com o Instituto Nacional de Estudos e Pesquisas Educacionais Anísio Teixeira - INEP, 102 pessoas trans - de um universo total de 8.721.946 inscritos - solicitaram usar o nome social no exame do ENEM ${ }^{6}$ no ano de 2014, primeiro ano em que há a possibilidade de se usar o nome social no exame. Em 2015 foram 278 solicitações e em 2016 foram 842, sendo 408 atendidas por ter apresentado a documentação exigida ${ }^{7}$. Portanto houve um acréscimo de 46\% em relação ao ano anterior. Em 2017 o número de solicitações para o uso do nome social por pessoas trans no ENEM foi de 303, contudo, o número de inscrições gerais também foi reduzido para 6,7 milhões.

BENTO (2014, p. 175) denominando este dispositivo de "uma solução à brasileira”, aponta para algumas singularidades do nome social:

O Brasil é o único país do mundo onde, no vácuo de uma legislação geral, instituições garantem um direito negado globalmente. Aqui transmutamos o respeito à identidade de gênero em "nome social". Universidades, escolas, ministérios e outras esferas do mundo público aprovam regulamentos que garantem às pessoas trans a utilização do "nome social". Mudar sem alterar substancialmente nada na vida da população mais excluída da cidadania nacional. Assim, por exemplo, uma estudante transexual terá seu nome feminino na chamada escolar, mas no mercado de trabalho e em todas as outras dimensões da vida terá que continuar se submetendo a todas as situações vexatórias e humilhantes e portar documentos em completa dissonância com suas performances de gênero. (BENTO, 2014, p. 175) [grifos da autora].

Mais adiante, esta autora problematiza o uso do nome social, reconhecendo que este mesmo que de forma precária e em poucos ambientes; é uma ferramenta institucional que reconhece a identidade de gênero das pessoas

6 ENEM é a sigla para Exame Nacional do Ensino Médio, o qual avalia o desempenho do estudante que conclui o ensino médio. É utilizado por muitas instituições de ensino superior para a seleção de seus novos estudantes.

7 Dados retirados do sítio do INEP. Para consultar: http://inep.gov.br/artigo/Lasset publisher/B4AQV9zFY7 $\mathrm{Bv} /$ content/nome-social-sera-usado por-mais-de-400travestis-e-transexuais/21206. 
trans em uma perspectiva não biologizante, na medida em que permite às pessoas reconhecimento sem a necessidade de laudos, isto é, prioriza a autoidentificação das próprias pessoas trans. Embora se possa concordar com a argumentação, também se pode questionar como seria possível tal situação, dado que a exigência de laudos não caberia a qualquer instituição de ensino, no sentido de aceitar ou recusar o acesso e a permanência dos/as estudantes. Tais pareceres tem a função de atestar uma "patologia" - que no caso das pessoas trans não apontaria para nenhuma necessidade extraordinária - não é atribuição pertinente aos estabelecimentos educacionais, até mesmo pela falta de profissionais capacitados para realizar estas funções. Por conseguinte, estes pareceres e laudos - ou quaisquer outros diagnósticos de enfermidades - não poderiam ser exigidos, contestados ou produzidos no âmbito das instituições de ensino.

Ainda que haja boa vontade, é precípuo que os direitos das pessoas trans não fiquem restritos à dependência desta "abençoada" graça. Ainda que esteja previsto o uso do nome social em algumas universidades públicas brasileiras, a permanência dos/as estudantes trans não é plenamente garantida, uma vez que, nem sempre esses arranjos são respeitados, através das mais estapafúrdias desculpas.

Em uma conversa informal com um rapaz trans graduando em numa universidade estadual, fui informado que um colega seu, estudante da mesma instituição, mas não do mesmo curso não estava conseguindo usar seu nome social nos documentos estudantis, bem como nas listas de chamada. Quando o mesmo foi buscar informações do por que do não uso de seu nome social (que já havia sido protocolado na secretaria do curso), a alegação foi a de que ele poderia utilizar-se do nome social quando tivesse retificado a sua documentação civil. Este é um exemplo de uma micropolítica de exclusão que Weber certamente ficaria tentado a chamar de um "tipo ideal”. Ora, o nome social é uma tentativa de garantir algum conforto às pessoas trans que por algum motivo ainda não conseguiram 
alterar seus documentos. Se é preciso primeiro haver a retificação civil da documentação, não há a menor necessidade do nome social. Mesmo explicando paciente e detalhadamente esta circunstância inusitada para a servidora pública responsável pela efetivação do uso do nome social naquela instituição, a negativa ainda permaneceu. Não houve acordo, a justificativa foi a de que o sistema (ou talvez o cistema) da universidade não permitia a alteração sem a devida mudança do registro civil, e de que "ela seguia ordens". Contudo, é importante ressaltar, que há outras ocasiões em que estudantes necessitam substituir sua documentação estudantil, especialmente nos casos em que o nome não foi corretamente descrito. Nestas ocorrências, o sistema não impede a modificação.

Assim, o rapaz foi impedido de utilizar uma garantia para o seu bem-estar na universidade, continuando a ter seu nome civil na lista de chamada, permanecendo a situação vexatória cotidiana. Neste sentido, o estudante foi penalizado por ser trans, ou por não ser cis. O que é penalizado é o que não está na norma, o anormal. Ser cis é a norma, portanto, ser trans transformase em ser anormal (contrário à norma). A escola (ou a universidade) são locais de vigilância da norma. E para se produzir a norma é preciso evidenciar o que é anormal, penalizando-a e instituindo a diferença deste pólos: normal x anormal. Como disse Foucault (2008), produzindo uma sanção normalizadora na forma de uma micro-penalidade:

\footnotetext{
Na oficina, na escola, no exército funciona como repressora toda uma micropenalidade do tempo (atrasos, ausências, interrupções dastarefas), da atividade (desatenção, negligência, falta de zelo), da maneira de ser (grosseria, desobediência), dos discursos (tagarelice, insolência), do corpo (atitudes "incorretas", gestos não conformes, sujeira), da sexualidade (imodéstia, indecência). Ao mesmo tempo é utilizada, a título de punição, toda uma série de processos sutis, que vão do castigo físico leve a privações ligeiras e a pequenas humilhações. Trata-se ao mesmo tempo de tornar penalizáveis as frações mais tênues da conduta, e de dar uma função punitiva aos elementos aparentemente indiferentes do aparelho disciplinar: levando ao extremo, que tudo possa servir para punir a mínima coisa; que cada indivíduo se encontre preso numa universalidade punível-punidora. (FOUCAULT, 2008, p.149).
} 
Não tive mais informações do estudante, não sabendo se ele finalmente conseguir resolver esta pendência.

Por fim, se o uso do nome social é permitido quando se é aluno/a regular de algumas das instituições de ensino superior, há o problema relatado na hora da prova de entrada, em que ainda não se é estudante, apenas pleiteante, logo, o direito ainda não está garantido. Ressalta-se que mais recentemente algumas universidades vêm utilizando nos seus exames de ingresso para a graduação o nome social. No entanto, ainda não tenho os dados de quais e quantas instituições, como também não posso informar se esta política de acesso nos locais em que está prevista, vem sendo cumprida corretamente.

A utilização dos sanitários no gênero ao qual se identificam as pessoas trans também é objeto de disputas. Disputas estas, assimétricas e não raro acirradas. Tais espaços muitas vezes são locais de diferenciação do gênero. A proibição do uso do banheiro no gênero identificado ou a exigência da utilização do banheiro "de acordo com sexo do nascimento" (argumentação bastante recorrente por quem é contrário ao uso do banheiro do gênero identificado por pessoas trans) é violento e reprodutor de estereótipos e de normas de gênero. Ou talvez seja violento por reproduzir estereótipos e normas de gênero. De qualquer forma, é plausível que pessoas trans reivindiquem usar o banheiro em que se sentem confortáveis. Se até mesmo frequentar sanitários é um exercício de negociação, as instituições de ensino parecem que se não se importam com a saída das pessoas trans, porém, com certeza o empenho para auxiliar em sua permanência ainda é muito pequeno e pouco efetivo.

Ou seja, se as políticas de acesso aos ambientes de ensino são ainda precárias para as pessoas trans, pior ainda é o quadro das políticas de permanência. Não se leva em conta que estudar é uma atividade que pressupõe dedicação, e para tanto o/a estudante precisa de um ambiente 
pacífico e tranquilo para exercer suas atividades estudantis. Quando o próprio ato de existir nestes espaços é fruto de muita paciência, esforço e disputa, não basta apenas ser estudante. Se a ideologia da meritocracia não se sustenta em uma observação mais crítica para quaisquer estudantes, para as pessoas trans ela não apresenta o menor fundamento. As opções são poucas: ou desiste-se de ser estudante, ou cria-se algumas estratégias de sobrevivência, ainda assim, esta sobrevivência não ocorre sem muitos percalços.

Muitas vezes busca-se uma atuação muito próxima da norma, ou do que se acredita que seja a norma esperada. E não à toa, muitas pessoas trans relatam que para resistir à escola, buscavam algum nível de adequação, mesmo tendo consciência desta atuação. Megg Rayara Gomes de Oliveira (2017) em seu livro "O diabo em forma de gente" explicita melhor o mencionado:

\footnotetext{
A escola, aparentemente, podia controlar meu corpo, mas não podia controlar meus segredos e aquele anjo higienizado por obra de um processo disciplinar não era real. Era uma personagem que eu interpretava cotidianamente e que me garantia certo sossego e invisibilidade, já que eu conseguia convencer a todos que estava internalizando suas imposições. Para fugir, ou ao menos suavizar algumas situações de constrangimentos, eu procurava controlar com certo rigor meus horários de chegada e de saída da escola [...]. (OLIVEIRA, 2017, p. 38).
}

Todavia, como já afirmado, nos dias de hoje o retorno aos estudos bem como a preocupação em ocupar a escola e/ou universidade tem sido frequentemente reivindicado pela população de pessoas trans brasileiras. Se as instituições de ensino são locais de exclusão, também o são de disputas de poder. As recentes demandas por parte das pessoas trans denotam a consciência da relevância das instituições de ensino, seja para a profissionalização, seja para a aprendizagem dos conteúdos historicamente acumulados, ou mesmo para a convivência neste importante lócus de socialização. A escola/universidade estão no centro das reivindicações 
atuais das pessoas trans. Cabem a estas instituições o debate científico e político para proporcionar tanto uma transformação na história estudantil destas pessoas, quanto uma transformação mais ampla, em que a escola/universidade reconheça seu papel de agente impulsionador das mudanças sociais necessárias em um país plural, diverso e democrático. Cabe acreditar ainda, em um papel transformador da Educação para a construção de uma sociedade mais justa, em que as instituições de ensino estejam livres da transfobia e sejam ambientes menos hostis à presença das pessoas trans.

\section{REFERÊNCIAS}

BENTO, Berenice. O que é transexualidade. São Paulo: Brasiliense Coleção Primeiros Passos, 2008.

- Nome social para pessoas trans: cidadania precária e gambiarra legal. Contemporânea - Revista de Sociologia da UFSCar, São Carlos, v. 4, n. 1, jan.-jun. 2014, pp. 165-182.

BUTLER, Judith. Problema de gênero: feminismo e subversão da identidade. 8. ed. Rio de Janeiro: Civilização Brasileira, 2015.

FOUCAULT, Michel. Em defesa da sociedade. São Paulo: Martins Fontes, 1988. - Aula de 17 de março de 1976.

. História da sexualidade 1: A vontade de saber. Rio de Janeiro: Graal, 1999.

. Vigiar e Punir. Nascimento da prisão. 35 ed. Petrópolis: Vozes, 2008.

LANZ, Letícia. O corpo da roupa: a pessoa transgênera entre transgressão e a conformidade com as normas de gênero. Curitiba: Universidade Federal do Paraná, Programa de Pós-graduação em Sociologia, 2014. (Dissertação de Mestrado). 
MORAES, Maria Célia Marcondes de. A teoria tem consequências: indagações sobre o conhecimento no campo da educação. Educação e Sociedade. Campinas, vol. 30, n. 107, p. 585-607, maio/ago. 2009.

OLIVEIRA, Megg Rayara Gomes de. O diabo em forma de gente: (r)existências de gays afeminados, viados e bichas pretas na educação. Curitiba: Editora Prismas, 2017.

SANTOS, Dayana Brunetto Carlin dos. Cartografias da transexualidade: a experiência escolar e outras tramas. Curitiba: Curitiba: Universidade Federal do Paraná, Programa de Pós-graduação em Educação, 2010. (Dissertação de Mestrado).

SCOTT, Joan. “Gênero: uma categoria útil de análise histórica”. Educação \& Realidade. Porto Alegre, vol. 20, no 2, jul./dez. 1995, pp. 71-99. 